\title{
Cataract surgery and retinal detachment: cause and effect?
}

Retinal detachment following cataract surgery is a serious and potentially sight threatening event that will often necessitate further surgical intervention. Because of the temporal sequence of events, any retinal detachment following cataract surgery is often assumed to be causally related to the cataract extraction. The evidence for this relation has been based on the observed frequency of such events following cataract surgery, particularly the excess frequency observed after intracapsular cataract extraction (ICCE) compared with extracapsular cataract extraction (ECCE). All these observations relate to surgical practice at least a decade ago and are characterised by the absence of a control group of patients who did not have cataract surgery and their experience of retinal detachment for comparison.

Some of the potential risk factors for retinal detachment following cataract surgery, that have been identified, may be classified according to: predisposing preoperative factors unrelated to the surgical procedure (myopia) ${ }^{1}$; intraoperative complications (vitreous loss, rupture of the posterior capsule with or without vitreous loss $)^{2}{ }^{3}$; and postoperative factors (capsulotomy surgical). ${ }^{3}$ Risk factors for idiopathic retinal detachment that have been identified include myopia, ${ }^{45}$ age, ${ }^{56}$ and lattice degeneration. ${ }^{6}$

The study by Norregaard and colleagues ( $p$ 689) presents estimates of the risk that a patient having a cataract extraction would have of experiencing a subsequent retinal detachment within 4 years of surgery, and are consistent with a comparable study on a US population. ${ }^{7}$ Both these studies confirm the observed excess frequency associated with intracapsular extraction, estimating that the risk is at least halved following extracapsular extraction with an intraocular lens implant (ECCE and IOL) compared with intracapsular extraction, and that the risk is higher for patients under the age of 70 years at time of surgery (p 689). ${ }^{7}$

Their estimates of risk for retinal detachment following cataract surgery (p 689) ${ }^{7}$ are based on data from large administrative health care databases which have the advantage of providing sufficient power to study infrequent events in a specified population that is covered by that data source. However, the assessment and interpretation of risk estimates from such data sources are limited by their inability to take account of the influence of factors that are possible confounders-for example, myopia ${ }^{145}$ and predisposing retinal degenerations. ${ }^{6}$ These may partly explain Norregaard et al's findings of excess risk following cataract surgery. Secondly, specific risk factors such as intraoperative events, ${ }^{23}$ cannot be fully assessed because this type of information is not routinely collected in these databases unless a specific intervention has been performed that is related to the primary procedure-for example, in this case an anterior vitrectomy.

While both Norregaard et als and Javitt et al $\mathrm{s}^{7}$ estimates indicate the cumulative risk within 4 years, the greatest risk is likely to be experienced within 1 year for any type of cataract extraction. In Norregaard et al's study about $60 \%$ of detachments following ECCE and IOL occurred within 1 year, with about a quarter occurring 3 years or later. This is consistent with previous reports which have indicated that up to $75 \%$ of detachments may occur within 1 year of surgery. ${ }^{389}$ These earlier onset detachments are often associated with a history of a predisposing intraoperative surgical complication. ${ }^{2} 8$ The frequency of detachment falls considerably after 2 years $^{9}$ and raises the question of whether these later onset events may be a direct consequence of the cataract extraction, or some other factors.
Measures of effect, such as relative risk, provide some assessment of the magnitude of an association between an exposure (cataract surgery) and the condition (retinal detachment), indicating the likelihood of developing the condition in the exposed group relative to those who are not exposed. The identification of a control group by Norregaard and colleagues permits this kind of assessment of the risk of retinal detachment associated with cataract surgery. Taking the standardised incidence ratios that are presented in this study (as estimates of relative risk), it would appear that the risk 4 years after surgery, for the ECCE and IOL group, is over 4.4 times that of the control group.

The relative risk indicates the strength of an aetiological (or causal) association between cataract surgery and retinal detachment. Assuming such an association is causal, relative risk does not provide any information about the amount of retinal detachment, among patients that have had cataract extraction, that is attributable to the surgery. This may be estimated by the attributable risk percentage (AR\%). ${ }^{10}$ Using the standardised incidence ratios for ECCE and IOL as estimates of relative risk, then the proportion of retinal detachment occurring within 1 year among patients who had cataract extraction (ECCE and IOL), that is attributable to the surgery (AR\%), can be estimated to be about $94 \%$. At 4 years after cataract extraction the AR\% is $77 \%$, suggesting that about a fifth of the observed detachments at 4 years may not be attributable to cataract surgery (ECCE and IOL).

As surgical practice developed from intracapsular to extracapsular extraction with intraocular lens implant, factors related to the type of cataract extraction and type of lens implant were found to compromise both preoperative examination and intraoperative manoeuvring in patients with subsequent retinal detachment. This made detachment surgery technically more difficult to perform, necessitating vitrectomy in some cases. ${ }^{2}$ Reattachment was achieved in about $76 \%$ of patients, with about $40 \%$ achieving a visual outcome of $6 / 18$ or better. ${ }^{2}$

As with previous reports, the findings of Norregaard and colleagues relate to clinical practice a decade ago during a period characterised by changing surgical technique and technological advances in intraocular lens design and development. Irrespective of whether or not the risks for retinal detachment have continued to fall with developments in surgical practice for cataract, an increasing volume of cataract surgery is now being performed, and is likely to continue to be so. Ophthalmic surgeons will continue to be managing pseudophakic patients presenting with a retinal detachment, whatever its likely cause. Surgical techniques for cataract have continued to evolve-for example, phakoemulsification with small capsulorhexis. It is possible that these, and other such developments, may have continued to challenge the management of pseudophakic detachment in that, now, more complex surgery may be more frequently indicated. Given that $80 \%$ of all patients achieve a good visual outcome of $6 / 12$ or better within 3 months of cataract surgery, ${ }^{11}$ this raises questions regarding what currently constitutes appropriate management of pseudophakic retinal detachment and what are the current clinical outcomes?

PARUL DESAI

Health Services Research Unit,

Department of Public Health and Policy, London School of Hygiene and Tropical Medicine, London WC1E 7HT 
1 Percival SPB, Anand V, Das SK. Prevalence of aphakic detachment. $\mathrm{Br} f$ Ophthalmol 1983;67:43-5.

2 McHugh D, Wong D, Chignell A, Leaver P, Cooling R. Pseudophakic retinal detachment. Graefes Arch Clin Exp Ophthalmol 1991;229:521-5.

3 Coonan P, Fung W, Webster RG, Allen AW, Abbott RL. The incidence of retinal detachment following extracapsular cataract extraction. A ten year study. Ophthalmology 1985;92:1096-101.

4 The Eye Disease Case-Control Study Group. Risk factors for idiopathic rhegmatogenous retinal detachment. Am $\mathcal{f}$ Epidemiol 1993;137:749-57.

5 Austin KL, Palmer JR, Seddon JM, Glynn RJ, Rosenberg L, Gragoudas ES, et al. Case-control study of idiopathic retinal detachment. Int $\mathcal{\Im}$ Epidemiol 1990;19:1045-50.
6 Burton TC. The influence of refractive error and lattice degeneration on the incidence of retinal detachment. Trans Am Ophthalmol Soc 1989;87:143-55. 7 Javitt JC, Vitale S, Canner JK, Krakauer H, McBean AM, Sommer A National outcomes of cataract extraction. I. Retinal detachment after in-patient surgery. Ophthalmology 1991;98:895-902.

8 Le Mesurier R, Vickers S, Booth-Mason S, Chignell AH. Aphakic retinal detachment. Br f Ophthalmol 1985;69:737-41.

9 Smith PK, Stark WJ, Maumenee AE, Enger CL, Michels RG, Glaser BM, et al. Retinal detachment after extracapsular cataract extraction with posterior chamber intraocular lens. Ophthalmology 1987;94:495-504.

10 Rothman KJ. Modern epidemiology. Boston/Toronto: Little, Brown, 1986.

11 Desai P. The National Cataract Surgery Survey: II. Clinical outcomes. Eye 1993;7:489-94. 